\title{
A Taxonomy of Views about Time in Buddhist and Western Philosophy
}

\author{
Kristie Miller
}

Department of Philosophy

The University of Sydney

Kristie_miller@yahoo.com

We find the claim that time is not real in both western and eastern philosophical traditions. In what follows I will call the view that time does not exist temporal error theory. Temporal error theory was made famous in western analytic philosophy in the early 1900s by John McTaggart (1908) and, in much the same tradition, temporal error theory was subsequently defended by Gödel (1949). The idea that time is not real, however, stretches back much further than that. It is common to hear it said that according to Buddhist philosophy (as though that were a monolithic view) time is illusory. While it is not true that, in general, either contemporary or ancient Buddhist scholars have thought time to be illusory, there are certainly some schools of Buddhist thought, such as that of traditional Dzogchen practitioners, according to which there is no time.

Much more recently the claim that time does not exist has arisen in the context of contemporary physics. Attempts to reconcile theories of macro-sized phenomena, described by the theory of general relativity, with theories of the micro, described by the theory of quantum mechanics, have been notoriously difficult. Indeed, it has proven near impossible to develop a unified theory of the macro and micro that does not substantially alter one or other of the theories of quantum mechanics or general relativity. Various strategies for developing a unified theory of quantum gravity - a theory that covers both the macro and the micro-are known collectively as timeless approaches to quantum gravity. Their advocates typically describe these theories as ones that jettison time, and their proponents take themselves to be endorsing temporal error theory. Defenders of this view include Barbour (1994a, 1994b, 1999, 1999), Deutsch (1997) and Rovelli (2004, 2007, 2009). ${ }^{\text {i }}$

Yet it seems unlikely that when McTaggart, Gödel, Barbour (et al) and Dzogchen practitioners say that there is no time, they are denying the existence of the same thing. Rather, it seems likely that each expresses a different proposition by the sentence "there is no time",ii. Realising that should also alert us to the likelihood that 
when different temporal realists - those who hold that time exists - assert "there is time" they too might express different propositions. Without knowing what proponents of temporal error theory mean when they deny the existence of time, we cannot know the extent to which they are in agreement with one another, nor the extent to which they are in disagreement with the temporal realist. Nor can we evaluate their claims about the non-existence of time.

In trying to determine which propositions the English sentences "there is no time" and "there is time" express, it is helpful to know what someone who asserts either sentence thinks it would take for there to be time. Quite generally if we want to evaluate some speaker's claim that "there is no X" we need to know, first, what the speaker supposes it would take for $\mathrm{X}$ to exist and, second, whether the world is a way such that given what it takes for $\mathrm{X}$ to exist, it turns out that $\mathrm{X}$ fails to exist. Mutatis mutandis if we want to evaluate a speaker's claim that "there is an X".

In the debate between temporal realists and temporal error theorists it is often far from clear what proponents of either view think it would take for there to be time, and thus far from clear what their grounds are for concluding either that there is time (in the case of the temporal realist) or that there is not (in the case of the temporal error theorist).

This paper is an attempt to set out a taxonomy of different views about what it takes for there to be time and, alongside that, a taxonomy of views about whether there is time or not, and if there is time what it is like. To be clear, however, the aim is not to attempt to settle facts about the world or to adjudicate the issue of whether or not the world is one in which there is time. The aim is limited to categorising kinds of temporal error theory and temporal realism in terms of two things (a) what each view takes to be necessary in order for there to be time and (b) what each view thinks about the way the world is with respect to those features.

Even within this limited scope it is not possible to categorise every view in either western or Buddhist philosophy, and it is not always possible to be sure in which category a particular philosopher or group of philosophers belongs. Notwithstanding this, it is still a useful categorisation for those interested in how time has been viewed in both the analytic and Buddhist philosophical traditions. It is also useful for those wishing to investigate the extent to which the views defended by temporal error theorists are substantially the same, or different, and the extent to which the views defended by temporal realists are substantially the same, or different. 
Indeed, as we will see, it may be that some temporal error theorists share more in common with some temporal realists than with other temporal error theorists and mutatis mutandis for temporal realists. Before I turn, in section 3, to begin a taxonomy of different views about what it would take for there to be time, it will be useful, first, to draw some distinctions regarding the nature of truth, on the one hand, and reality, on the other hand. I now turn to that task.

\section{Truth and Reality}

There is no single set of distinctions that will allow us straightforwardly to map notions in Buddhist thought onto those of contemporary metaphysics. Having said that, there are some distinctions that will prove useful going forward. To that end, let us introduce a tripartite distinction between ultimate truths, derivative truths, and conventional truths. Ultimate truths are those that correspond to the nature of reality, in and of itself: that is, independent of any facts about us including our ways of conceptualising reality and our particular perspectival interests, preferences or desires. Corresponding to ultimate truth, then, is ultimate reality; ultimate reality is the domain of things about which ultimately true or false statements can be made. According to most Buddhist traditions ultimate reality is composed of simples (partless entities) that have a single intrinsic nature. It is worth bearing in mind that this additional claim about what it would take for there to exist an ultimate reality is not one that all contemporary metaphysicians would accept. For instance, one might be a structuralist who holds that, fundamentally, what exists are structures, and since structures are defined relationally this view would deny that ultimate reality must be such that its components have a single, intrinsic, nature.

Derivative truths, by contrast, are those that are made true in part by how the world is, ultimately, (by ultimate reality) and in part by the ways in which we conceptualise that reality and by the perspectives, preferences, projects, and desires that we have. Let us call derivative reality the domain of things that makes true, or false, derivative truths. So, for instance, that strawberries are red would seem to be a derivative truth.

We can now say that any statement, $\mathrm{S}$, is strictly speaking true, iff $\mathrm{S}$ is ultimately true, or $\mathrm{S}$ is derivatively true. 
That brings us to conventional truths. Following Siderits and Katsura (2013), let us say that conventional truths are truths such that action based on their acceptance reliably leads to successful practice. For instance, it would seem to be a conventional truth that there is an external world, since acting as though this is so generally has practical benefits. We can divide the conventional truths into those that are either ultimately or derivatively true, and those that are neither ultimately nor derivatively true. Call the former grounded conventional truths, and the latter mere conventional truths. If there really is an external world, then the conventional truth that there is an external world is a grounded conventional truth. Indeed, the reason why it is practically useful to act as though there is an external world is that there is.

Mere conventional truths, by contrast, are not really truths at all since they are neither ultimately nor derivatively true. If one supposes the set of statements that compose a discourse, $\mathrm{D}$, to be mere conventional truths, then one is an error theorist about discourse D. Let us call such a person a mere conventionalist about D. Mere conventionalism is a kind of error theory; but rather than being an error theory that embraces some sort of eliminativism about discourse D, the mere conventionalist thinks that we ought to go on engaging in the relevant discourse because it has certain practical benefits. Thus contemporary moral fictionalism is one kind of mere conventionalism; but it is not the only kind of mere conventionalism.

3. What does it take for there to be time?

To aid in our taxonomy I will introduce three categories. In essence the categories differ with respect to how high they set the bar for our world being one in which there is time. I will say that a view sets the bar high if that view requires that in order to have time our world must contain a fairly rich metaphysical structure. By contrast, a view sets the bar low if that view requires that our world have only a minimal metaphysical structure in order to have time. The three categories I introduce are the hard-nosed category, the middle-way category and the undemanding category. Each of these differs with respect to how high they set the bar.

\subsection{Hard-Nosed Category}


The hard-nosed category encompasses views that set the bar high. These views are ones according to which in order for there to be time the world must be genuinely dynamical. It must either be that moments come into and pass out of existence, or else that which moment is present, changes, so that a moment is in the future, then moves to being the present, and then recedes to being in the past. A quick note of clarification here is in order. Henceforth I talk about the existence of moments (or times), and of the movement (or lack thereof) of the present moment. In Buddhist philosophy it is more common to talk of the coming into, and passing out of, existence of events (or objects and properties). My talk of moments, or times, is supposed to be neutral regarding what a moment is, and is consistent with a moment being a set of appropriately related events, objects, and properties.

In the western tradition McTaggart is probably the first to systematically articulate a hard-nosed view. Indeed, it is McTaggart who sets out much of the apparatus in terms of which views on the nature of time are later defined. He differentiates between two orderings of events or instants: the A-series and the Bseries. The B-series is a way of ordering events in terms of the relations of earlier than, later than and simultaneous with. These relations are unchanging. If the extinction of the dinosaurs is earlier than the birth of Nixon, then the B-relation that obtains between those two events is invariant and static. The A-series orders events in terms of whether they are objectively past, present or future. For any time in the Aseries, that time instantiates a particular A-theoretic property (pastness, presentness or futurity) that determines its place in that series. The location of events within the Aseries is dynamic: a set of events, $E$, will be present, is future, and will become past.

The hard-nosed category encompasses views according to which in order for there to be time there needs to be an A-series ordering of events that is irreducible to $\mathrm{B}$-series relations. On such views what it takes for there to be time is for there to be some dynamical movement of an objectively present moment and hence for there to be dynamically changing temporal facts. Thus on such views it is an essential feature of time that it flows, where temporal flow is characterised by the movement of the present or the change in facts about which moment is present. According to these hard-nosed views, then, it is also an essential feature of time that it is anisotropic. A dimension has the property of being anisotropic if there is some difference between the properties of that dimension in one direction compared to the other. So time is 
anisotropic if there is a difference in its properties when we consider the earlier-tolater direction as opposed to the later-to-earlier direction.

It is easy to see why hard-nosed views are committed to the idea that it is essential to time that it is anisotropic. For if time flows then it must flow in a direction, and A-theorists suppose that in fact it flows from past to future and not the reverse. Thus, necessarily, time has a direction and flow, and is essentially dynamical.

\subsection{Middle-Way Category}

By contrast, the middle-way category is a category of views that set the bar somewhat lower than do views in the hard-nosed category. They set the bar somewhere in the middle. It is worth reiterating at this point that views in this category are views about what, at a minimum, a world needs to be like to contain time. They are not views about the way the world is; it is consistent with such views that our world contains a rich metaphysical structure such as a dynamical A-series. It is simply that, according to this view, a rich metaphysical structure is not necessary for there to be time.

Views in the middle-way category share the idea that what it takes for there to be time is for there to be an ordering of events by the relations of earlier-than, laterthan, and simultaneous-with (the B-relations) and for that ordering to be anisotropic. We could partition middle-way views into those according to which this anisotropy must be intrinsic to time, and those according to which it can be extrinsic. A dimension is intrinsically anisotropic if it is a feature of the very dimension itself that it is anisotropic; a dimension is extrinsically anisotropic if the contents of the dimension have some asymmetry that grounds a temporal anisotropy. Thus spatial relations are isotropic — space itself is not intrinsically anisotropic_-but some regions of space might be extrinsically anisotropic if the properties of things in space going one direction are different from the properties going some other direction. Bits of space containing moving walkways are extrinsically anisotropic since moving in one direction is quite different to moving in the other direction. Thus we could divide the middle-way category into a hard-nosed middle way category, according to which in order for there to be time, time must be intrinsically anisotropic, and an undemanding middle-way category according to which time must be anisotropic, either intrinsically or extrinsically. For simplicity, however, I will treat this as a unified category. 
Those middle-way views that hold that time must be, at a minimum, extrinsically anisotropic, suppose that, at a minimum, the contents of time must be asymmetric in some manner; there is then debate about which asymmetry of content can ground temporal anisotropy. There are two promising suggestions. The first appeals to causal asymmetry: the idea is that causation is temporally asymmetriccauses either always or typically precede their effects (Horwich 1989). The second appeals to certain de facto asymmetries in the arrangements of events at, and across, times. The idea is that it follows from statistical mechanics that there are many more possible micro-states of the world that are, at the macro-level, disordered, than microstates that are, at the macro-level, ordered. Given that the world is now in some particular macro-state, $\mathrm{S}$, it is more likely that the macro-states earlier and later than $\mathrm{S}$ are less ordered than S. So far we find no asymmetry. But if we plug into this picture the claim that very early moments of the universe were characterised by a highly ordered macro-state (typically known as the past hypothesis (Albert 2000; Kutach 2011)) then this, combined with statistical mechanics, entails that entropy will, in general, increase away from this highly ordered macro-state. Thus the contents of time will be asymmetric: the contents will go from highly ordered to progressively less ordered. Indeed, on this view the earlier-to-later direction is simply the direction that moves away from the low entropy boundary condition. As with all views in the middle-way category, what is not required for there to exist time, contra those who embrace a view in the hard-nosed category, is for there to exist monadic, dynamical, properties of pastness, presentness and futurity.

\subsection{Undemanding Category}

Views that fall under the undemanding category are, unsurprisingly, views that set the bar low. According to such views all it takes for there to be time is for there to be an invariant ordering of moments in terms of the B-relations. What is not required is that time flows, or that time is anisotropic. ${ }^{\mathrm{iii}}$ According to such views there can be time even if there is no global difference between one temporal direction and the other, reverse, direction. On this view temporal relations are similar (in certain respects) to relations such as greater-than, equal-to, and less-than: these latter relations order the natural numbers in a real, objective, ordering, but there is no sense in which the natural numbers really go from less-than to greater-than rather than from greater-than 
to less-than. Undemanding views hold that the world can offer fairly meagre metaphysical resources and there still be time. In part that is because proponents of such views hold that what the hard-nosed and middle-way views take to be essential features of time are not really features of time, but instead are subjective features of the way that some beings located in time perceive the world. Thus, according to such a view, the hard-nosed and middle-way views are both misattributing, as essential features of time, features that really attach to psychologies in time. I will consider this in more detail shortly.

\section{A matrix of views}

So far I have laid out three broad categories of views about what is necessary for time to exist. As noted previously, that alone does not tell us anything about whether the proponents of those views are temporal realists or temporal error theorists. In what follows I put together a taxonomy of views that have appeared in the literature in terms of two things: (a) what those views say about what is required for the existence of time and (b) what those views say the world is like with respect to what is required for the existence of time. Below is a table that represents the matrix. The three rows represent each of the categories of views regarding what it takes for there to be time. The two columns represent views about whether the world includes at least those features, or not. Thus hard-nosed realists will locate themselves in the top left hand box since they set the bar high regarding what the world needs to be like in order to contain time, but they also think that the world is that way. Hard-nosed error theorists agree with hard-nosed realists about what is required for there to be time, but disagree that the world is that way. Middle-way realists locate themselves in the middle left hand box. They set the bar in the middle regarding what they think is necessary for there to be time, and they think the world has (at least) the necessary structure for time to exist. Middle-way error theorists locate themselves in the middle right hand box. Middle-way error theorists agree with middle-way realists about what the world needs to be like in order for it to contain time, but they disagree with middle-way realists that the world is that way. Finally, the bottom row has undemanding realists in the left hand box and undemanding error theorists in the right hand box. Undemanding realists and undemanding error theorists agree about how the world needs to be in order to contain time, but they disagree about what the world is like: 
the undemanding realist thinks the world has (at least as much of) the metaphysical structure required to contain time, and the error theorist thinks it does not.

\begin{tabular}{|l|l|l|}
\hline & Realists & Error Theorists \\
\hline Hard-nosed Category & Hard-nosed realists & Hard-nosed error theorists \\
\hline Middle-way Category & Middle-way realists & Middle-way error theorists \\
\hline Undemanding Category & Undemanding Realists & $\begin{array}{l}\text { Undemanding } \\
\text { theorists }\end{array}$ \\
\hline
\end{tabular}

Let us consider, first, hard-nosed realists. In contemporary metaphysics those known as A-theorists are hard-nosed realists. So included in the top left hand box we find the following contemporary philosophers of time: Tooley (2000) Zimmerman (2008), Forrest (2006), Bourne (2006), Crisp (2003), Fine (2006), Tallant (2008) and we could include many more. There are three kinds of hard-nosed realist view. The first of these is presentism. According to presentists, only the present moment is real: only presently existing objects and events exist; there are no past or future objects or events. But which moment is the present changes and thus which objects and events exist, changes. Presentism is usually contrasted with eternalism, the view that past, present, and future, events and objects are equally real. Presentists and eternalists thus disagree about which moments exist, or, if you prefer, they disagree about whether past or future objects and events exist.

The same two positions regarding ontology can be found in Buddhist thought. The Sautrāntikas and Theravādins hold that only present events and objects exist. They are presentists. By contrast, the Sarvāstivādins hold that past, present, and future objects and events are equally real and there exist static B-relations of earlier-than, later-than, and simultaneous-with, that hold between such events. They are eternalists.

It is straightforward to see that the Sautrāntikas and Theravādins are hardnosed realists. According to such views the world is genuinely dynamical as new events and objects come into, and pass out of, existence.

By parity, it would be easy to suppose that eternalists, such as the Sarvāstivādins, turn out to be middle-way or undemanding realists. For, on the face of it, it seems that eternalists must deny what the hard-nosed realist takes to be essential 
for there to exist time: namely that there is an objectively present moment that moves. If that is right, then the eternalist who holds that time exists is not a hard-nosed realist, but she is a realist of some kind.

It is, however, false that eternalists must deny what the hard-nosed realist takes to be essential for the existence of time. To be sure, most versions of eternalism are inconsistent with hard-nosed realism. B-theoretic versions of eternalism are usually known as block universe theories because they conceive of the universe as a four-dimensional block in which time is one of the four dimensions. The block as a whole does not undergo any change; events are related by static B-relations. Whatever is true of the block, is, tenselessly, true of the block. If the world is as block universe theorists suppose it to be, then hard-nosed realism is false and some other kind of realism is true.

Not all versions of eternalism are, however, like this. The moving spotlight theory combines an eternalist ontology with the claim that there exists a moving now. In contemporary metaphysics such a view has been defended by, inter alia, Skow (2012) and Cameron (2015). According to such a view, although past, present, and future events and objects are equally real, and static B-relations obtain between events and objects, only one set of those events and objects are present — that singled out by the spotlight of nowness - and which moment is the present changes as the spotlight moves. The moving spotlight view is a second version of the A-theory, sitting alongside presentism. For it holds that the world is genuinely dynamical: facts about which moment is objectively present change, and time flows as presentness moves.

One way of unpacking the metaphor of a moving spotlight is in terms of causal efficacy. On such a view what it is for a moment to be objectively present is for it to be the only moment that is causally efficacious and for that causal efficacy to move from moment to moment. Contemporary hard-nosed realists who think that moments other than the objective present exist, often ground a difference between past, present, and future moments by holding that only present moments are causally efficacious. We find such claims made not only by moving spotlight theorists, but also by A-theorists who embrace the growing block theory. The growing block model is a third kind of A-theory. On this model past events and objects exist, but future objects and events do not. The world is genuinely dynamical because new events and objects are constantly coming into existence: so the sum total of reality is evergrowing. The view is known as the growing block because there exists a block 
universe of events, all related by static B-relations, with the very last moment in the block being the objectively present moment. Yet the block grows as new moments are added to it and the moment that was the objectively present moment becomes objectively past, and a new moment becomes objectively present. This view is defended by, inter alia Forrest (2006) and Tooley (2000).

Both the moving spotlight view and the growing block view are versions of hard-nosed realism, since according to both views the world is dynamical, there is an objectively present moment, and which moment is present, changes. But one view (the moving spotlight view) embraces an eternalist ontology and the other (the growing block view) embraces an ontology mid-way between eternalism and presentism.

So although the Sarvāstivādins are eternalists, it does not follow from this they must reject hard-nosed realism and instead embrace middle-way (or undemanding) realism. And indeed, when we examine their view further we find that they want to distinguish past, present and future, and do so by hypothesising that the difference between these times is that only the present moment is causally efficacious. If, according to the Sarvāstivādins, there is something special about the present moment that marks it out from past and future moments, then although they are eternalists, the Sarvāstivādins are not block universe theorists. Instead, their view looks like a version of the moving spotlight view. For they think the present is special in one way: it is the only moment that is causally efficacious. Since which moment is present, changes, it follows that the Sarvāstivādins are best thought of as moving spotlight theorists, and, therefore, as hard-nosed realists.

Amongst hard-nosed realists such as the Sarvāstivādins we also find Longchenpa (1308-1363) who was a member of the Dzogchen tradition. Like others in that tradition, he distinguishes four times. The first three of these are the ceased, the not-lingering and the not-yet-coming. These map onto the past, the present and future. The description of these three times is dynamical: the not-lingering is that which passes into the past and the not-yet-coming is that which becomes the not-lingering and eventually the ceased. In Dzogchen thought the three times belong to our ordinary, conventional world and are essentially dynamical. Longchenpa, following others in the Dzogchen tradition, also distinguishes a fourth time, known as timeless time. Within the Dzogchen tradition timeless time is typically held to be a changeless, complete, non-altering ground. It is timeless time that is real (Yao 2007). 
Timeless time is the time associated with enlightenment. Thus, according to most Dzogchen practitioners, since there is no change in the enlightened state there is also no time. In this, traditional Dzogchen practitioners agree with McTaggart (1908) who argued that without real change, there can be no time.

If we return to our earlier distinction between conventional, derivative, and ultimate truth, it seems clear that traditional Dzogchen practitioners suppose that hard-nosed temporal error theory is ultimately true. It also seems that they hold that hard-nosed realism is conventionally true because the conventional world can be described in terms of dynamical change amongst the-ceased, the not-lingering and the not-yet-coming. But, it would seem, if the ultimate truth is hard-nosed error theory, then this conventional truth must be merely conventional (for it cannot both be that hard-nosed error theory is true, and that hard-nosed realism is true). Thus, according to orthodox Dzogchen practitioners, there is an illusion as-of hard-nosed realism being true.

Longchenpa's understanding of timeless time, however, is somewhat different. He takes timeless time to be essentially dynamical. According to Yao (2007), timeless time is characterised by coming-to-presence. It is the self-organising principle of the highest reality. According to Longchenpa it is ultimately true that timeless time is dynamical. Since timeless time is real time (it is part of ultimate reality) it follows that Longchenpa, by contrast to other Dzogchen practitioner, ought to be categorised as a hard-nosed realist. For ultimate reality, according to Longchenpa, is essentially dynamical.

That brings us to Dōgen. According to some interpretations of Dōgen he too is a hard-nosed realist. Dōgen (1200-1253) was a Japanese Zen Buddhist who wrote extensively on what he called Being-Time (Uji). The correct interpretation of Dōgen is controversial. According to traditional interpretations, Uji means something like time is being and all being is time. On this interpretation Uji is the dynamical activity of the becoming of all things (Heine 1985; Stambaugh 1990). Read this way Dōgen ought straightforwardly to be classed as a hard-nosed realist. Indeed, read this way he sounds remarkably like some contemporary hard-nosed realists who think that temporal relations consist entirely in the coming into existence of new objects and properties and, in some cases, the passing out of existence of objects and properties (Tallant 2014). 
In contrast to this interpretation, however, Vorenkamp (1995) argues that Dōgen's view of time is similar to the view that all that is required for there to be time is the existence of static B-relations. Vorenkamp argues that Dōgen's view is similar to those of the middle-way realist because Dōgen is properly interpreted as holding that the appearance of temporal passage is not an objective feature of time itself, but rather, the result of our subjective perspective. The idea is that for Dōgen the dharmapositions are four-dimensional and do not move relative to one another (and indeed, could only do so if there were some additional dimension relative to which they could move, such as meta-time). Thus static relations hold between the dharma-positions and the what-Now-is-no-longer and the what-Now-is-not-yet. Thus according to Vorenkamp the Uji can be thought of as a four-dimensional manifold in which the temporal relations between the individual dharma-positions are static B-relations. So far, then, Dōgen looks like a middle-way realist.

That is not, however, the end of the story. Vorenkamp recognises that Doggen also seems to embrace the idea that there is a change of events with respect to time. For Dōgen, tense is real- events change with respect to their tensed properties and temporal becoming is a real feature of the world. One way of making sense of this, suggested by Vorenkamp's reading of Dōgen (though Vorenkamp does not argue for this interpretation) is that Doggen holds a version of the moving spotlight view. This would accord with the idea that, for Dōgen, all events have a static position in a fourdimensional manifold, alongside the idea that tense is real, since according to the moving spotlight view which events are present is an objective feature of the world. However we understand the reality of tense in Doggen, it follows that he ought be classed as a hard-nosed realist, though exactly which kind of hard-nosed realist he is will depend on how one understands his commitment to the reality of tense.

That brings us to the box on the top right. Inhabitants of this box are hardnosed error theorists. The hard-nosed error theorist sets the bar high in terms of what is required in order for there to be time, and, she concludes, our world turns out to lack the features required for time. McTaggart (1908) is a clear case of a hard-nosed error theorist. He argues that in order for there to be time there must be a dynamical A-series. For, he thinks, in the absence of an A-series there would be no change in the world, and in the absence of change there would be no time. But, he argues, a dynamical A-series is internally inconsistent. For any time, $t$, that is future will be present and will then be past. So every time must have all three properties of being 
future, present, and past. But no time can have all three properties since these properties are incompatible. Yet if a time has only one property-say the property of being future - then time does not pass since $t$ is always future, and is never present and then past. The only way $t$ could all have three properties would be if it had them one at a time: first futurity, then presentness, then pastness. But that is only possible if there is some further dimension relative to which $t$ itself can change its properties, and that would require that there is a second temporal dimension (meta-time or hypertime). But if there were a second dimension relative to which times can change then we could ask all of the same questions about the times in that higher-order temporal dimension, and we would either have to conclude that the second temporal dimension is static, in which case the totality of time and meta-time is static, or we would need to posit an infinite regress of temporal dimensions to explain how meta-time can be dynamical. In either case, McTaggart concludes, there is no time because what would be required for there to be time turns out to be not merely contingently non-existent but, in fact, impossible.

Gödel (1949) is another hard-nosed error theorist. Like McTaggart he holds that time exists only if there exists an A-series. But, he thinks, if two worlds share the same laws of nature then if there is time in one there must be time in the other. $\mathrm{He}$ then shows that there are solutions to Einstein's field equations that represent physically possible worlds (that is, worlds with the same laws of nature as our world) in which there is no A-series. But if such worlds lack an A-series and therefore lack time, then, he reasons, our world must also lack time since it shares the same laws. Thus, he concludes, hard-nosed temporal error theory is true.

The table, below, shows the first row populated. You will notice that a figure that has not yet been discussed, Nāgārjuna, appears in both rows, and that his name is prefaced with the phrase "rejected by", and, in one case, that is followed by a question mark. This might seem puzzling, and so it is to Nāgārjuna that I will now turn.

\begin{tabular}{|l|l|l|}
\hline & Realist & Error theorist \\
\hline Hard-nosed category & Presentists: Tallant, Crisp, Bourne, & McTaggart, Gödel, \\
& Zimmerman; Sautrāntikas, & traditional Dzogchen \\
& Theravādins. & practitioners \\
& Growing block theorists: Tooley, & Rejected by Nāgārjuna? \\
\hline
\end{tabular}




\begin{tabular}{|l|l|l|}
\hline & Forrest. & \\
& Moving spotlight theorists: Skow, \\
Cameron, Sarvāstivādin school, & \\
Dōgen, & & \\
Other Dynamical Views: & Longchenpa, \\
Rejected by Nāgārjuna & & \\
\hline Middle-way Category & & \\
\hline Undemanding Category & & \\
\hline
\end{tabular}

Nāgārjuna is widely considered to be the founder of the Madhyamaka school of Mahāyāna Buddhism, and he explicitly considers the nature of time in his Mūlamadhyamakakārikā. In what follows I will first consider Nāgārjuna's arguments about the nature of time, before turning to put these in the context of his work more broadly. It will be interesting to do so, in part, because the arguments bear some strong similarities to those that we find offered by McTaggart many centuries later.

Here is how Nāgārjuna's arguments proceed. If the past, present, and future are real properties of the world, (if they are part of ultimate reality) then either the future and the present depend on the past or they do not. Suppose they do depend on the past. For Nāgārjuna, if X depends on Y, then X's existence necessitates Y's existence. Now, it must be that either the present and the future exist in the past or they do not. Suppose they do not. If they do not, then the thing upon which they depend - the past-exists without necessitating the existence of the present and future. But if so, it cannot be that the present and future depend on the past. On the other hand, if the present and future do depend on the past then they must exist in the past, for the past must necessitate their existence. But the present and future cannot exist in the past and still be present and future. The general thought here is that when the past was around to ground the present and future, they were not around to be thus grounded, and when the present and future are around to be grounded by the past, the past is not around to do the grounding. Thus it cannot be that the present and future depend on the past. 
Suppose, then, that the present and future do not depend on the past. That cannot be, for if the present does not depend on the past, and the future does not depend on the present, then there is no sense in which the events of the past, present and future, are in the same time-line. If time is a relation in which events stand, then an event is only past relative to some other event, and future relative to some still other event. If we have a single time-line of events then they must be related in this way, and so there must be dependency relations between them: the present and future must depend on the past.

So either the present is in the past because it depends on the past, in which case it is nonexistent since it is not the present, or the present is independent of the past, in which case it is also nonexistent because to be the present is to stand in some relation to the past and that relation would be absent. Thus, past, present, and future, cannot be intrinsic features of time, and truths about time cannot be ultimate truths.

What these arguments show is that the world is not a certain way: it is not a way that would make true hard-nosed realism. So we can be assured that Nāgārjuna rejects hard-nosed realism. But his arguments leave open that Nāgārjuna might be a hard-nosed error theorist, or that he might be some sort of less demanding realist. Most of Nāgārjuna's interpreters conclude that he is neither a hard-nosed realism nor a hard-nosed error theorist. Instead, he is taken to be undermining some key presupposition that both the hard-nosed error theorist and the hard-nosed realist accept: namely that it makes sense to suppose that facts about past, present, and future, are intrinsic features of time and then ask whether the world is such that those intrinsic properties exist. If that is right, then, on the face of it, Nāgārjuna also rejects hard-nosed error theory. So it would be tempting to conclude that by rejecting the presupposition that hard-nosed realists and error theorists share, Nāgārjuna ought be classified as either a middle-way or undemanding realist: someone who thinks that what is required in order for there to be time is something more minimal.

Before we draw that conclusion, however, let us consider Nāgārjuna's view about time in the context of the other arguments he mounts in the Mūlamadhyamakakārikā. Nāgārjuna's aim in the Mūlamadhyamakakārikā is to argue for the claim (central to Mahāyāna Buddhism) that everything is empty (Siderits and Katsura (2013) and Kalupahana (1974) Garfield (1995)). To say that everything is empty is to say that nothing has an intrinsic nature. Thus, given what Buddhist scholars think it would take for there to be an ultimate reality (namely that the entities 
in that domain have a single, intrinsic, nature) this is to argue that there is no ultimate reality and thus there are no ultimate truths.

Viewed this way we can think of Nāgārjuna as rejecting hard-nosed realism and hard-nosed error theory, but not thereby as endorsing some other kind of realism about time. For if everything is empty then there are no ultimate truths. And if there are no ultimate truths, then there are no derivative truths either. On the assumption that any form of realism (middle-way or undemanding) is true only if there are some ultimate truths, it follows that Nāgārjuna rejects all forms of temporal realism. That, in turn, brings up full circle. For if all truths are merely conventional truths, then it seems as though Nāgārjuna is a global error-theorist. Since he explicitly thinks that we can go on using the language we do, and engaging in the practices in which we engage, because these are practically useful, it would perhaps be better to say that viewed this way Nāgārjuna looks like a global fictionalist: someone who thinks there are no truths, properly speaking, but that we can and should continue to engage in our current discourses and retain our current practices. Interpreted this way, Nāgārjuna is both a hard-nosed error theorist, a middle-way error theorist and an undemanding error theorist, since he supposes that what it would take to be any kind of temporal realist at all would be for there to be some ultimate truths, and it turns out there are no such truths. Thus to say that Nāgārjuna is for instance, an demanding error-theorist and, as it were, leave it at that, is misleading, since it implies that he agrees with the demanding realist regarding what would be required to vindicate temporal realism; but that is plainly false.

Understanding Nāgārjuna as a global error-theorist cum fictionalist might, however, seem perplexing. It seems clear that one of the aims of the Mūlamadhyamakakārikā is to show that no ultimate reality is required in order for our everyday claims to be conventionally true. Thus one might interpret Nāgārjuna as, in some good sense, rejecting the taxonomy of truths I offered earlier. If no ultimate reality is required for our ordinary claims to come out as (conventionally) true then one might wonder if conventional truths is, in the end, just truth. Interpreted this way, Nāgārjuna might be thought of as an early defender of a deflationary theory of truth, according to which there is nothing to truth except the T-schema: ' $x$ ' is true iff $x$. Viewed as a deflationist about truth, Nāgārjuna is best thought of not only as arguing that there are no ultimate (or derivative) truths because there is no way the world is, ultimately, but also that there are no ultimate (or derivative) truths, because those 
notions of truth simply make no sense. But there are truths nonetheless: conventional truths. Interpreted this way, Nāgārjuna would not be rightly classified as a global error-theorist cum fictionalist. Instead, whether Nāgārjuna is a realist or error theorist about some particular phenomenon, such as time, would depend on which conventional truths obtain and which do not. Since arguably Nāgārjuna's arguments give us reason to reject the idea that pastness, presentness and futurity are even, conventionally speaking, features of time, it seems most charitable to think that Nāgārjuna thus interpreted is best classified as some sort of middle-way or undemanding realist. To depict these points of difference I represent Nāgārjuna qua global fictionalist as Nāgārjuna(1) and Nāgārjuna qua truth deflationist as Nāgārjuna(2) in the table below:

\begin{tabular}{|c|c|c|}
\hline & Realist & Error theorist \\
\hline Hard-nosed category & $\begin{array}{l}\text { Presentists: Tallant, Crisp, } \\
\text { Bourne, Zimmerman; } \\
\text { Sautrāntikas, Theravādins. } \\
\text { Growing block theorists: } \\
\text { Tooley, Forrest. } \\
\text { Moving spotlight theorists: } \\
\text { Skow, Cameron, } \\
\text { Sarvāstivādin school, } \\
\text { Dōgen, } \\
\text { Other Dynamical Views: } \\
\text { Longchenpa, }\end{array}$ & $\begin{array}{l}\text { McTaggart, Gödel, } \\
\text { traditional Dzogchen } \\
\text { practitioners } \\
\text { Nāgārjuna(1) }\end{array}$ \\
\hline Middle-way Category & $\begin{array}{l}\text { Albert, Callender and } \\
\text { Suhler, Ismael, Mellor, } \\
\text { Horwich, Nāgārjuna(2) }\end{array}$ & Nāgārjuna(1) \\
\hline Undemanding Category & Nāgārjuna(2) & Nāgārjuna(1) \\
\hline
\end{tabular}

The next row of the matrix has middle-way realists on the left and middle-way error theorists on the right. According to contemporary middle-way realists there exists only a manifold of static temporal relations. No moment is singled out as 
metaphysically special. Many versions of the block universe theory fall into the category of middle-way realism. According to such views we can, however, make sense of talk of the past, present, and future in the same way that we make sense of talk of here and there. Just as 'here' refers to wherever the speaker happens to be (it is an indexical) likewise 'now' or 'the present' refers to whichever moment the speaker happens to be at. And just as 'here' is not some mysterious spatial property that moves around depending on where you happen to be, neither is 'now' a mysterious temporal property that moves (Mellor 1981).

Moreover, say middle-way realists, if it seems to us as though time passes then that is an illusion caused by our subjective location(s) within time. It might seem as though the past, present and future are very different from one another because each time-slice that partially composes a temporally extended person is in causal contact with a different moment. ${ }^{\text {iv }}$ Since causation is by and large temporally asymmetriccauses typically precede their effects - we typically know much more about the past than the future, for we typically have memories of past, but not future, moments. It therefore makes sense for time-slices to deliberate about matters that are in the future, but not those in the past. This leads us mistakenly to suppose that there is something metaphysically special and the present moment, and that the past is fixed and the future is yet to be determined. But this is merely the result of our subjective experience of successive moments in time combined with certain asymmetries in causation and knowledge (Ismael 2002; Callender and Suhler 2012). Thus middleway realists share the idea that it is not necessary, for time to exist, that there is a genuinely dynamical dimension of our universe. Instead, the appearance of such a dimension is explained as the result of our subjective perspective on a set of static temporal relations. (Albert 2000; Callender and Suhler 2012; Ismael 2002; Mellor 1981; Horwich 1989).

It is unclear whether there are any contemporary middle-way error theorists, though it is easy to see how one could come to be so. For instance, one might accept that dynamism is not necessary for the existence of time, but think that intrinsic anisotropy is essential to time. If one then concluded that there is no intrinsic anisotropy, then one would become a middle-way error theorist.

Finally we come to the last row in our matrix. It represents those, in the left hand box, who are undemanding realists, and those, in the right hand box, who are undemanding error theorists. 
Contemporary undemanding realists hold that in order for there to be time there must exist a manifold of events such that there is a fact of the mater regarding the spatio-temporal distances between those events. There needs to be a partial ordering of events in terms of the asymmetric B-relations. ${ }^{v}$ But not only does there not need to be any objective, dynamical, monadic A-properties, neither is it essential to time that it is (globally) anisotropic. On this view there is nothing importantly different between the temporal direction that goes from what we call earlier-to-later, and what we call later-to-earlier. Indeed, on this view it is an entirely perspectival matter which moment is the first moment and which is the last moment. It is entirely perspectival whether $\mathrm{A}$ is earlier than $\mathrm{B}$, or B is earlier than $\mathrm{A}$. Due to this, some undemanding realists are known as temporal perspectivalists. According to temporal perspectivalists, not only is the apparent flow of time a subjective feature of our psychologies, so too is the apparent direction of time.

Perspectivalists suggest that our subjective experience as of time having a direction is due, in part, to contingent features of the distribution of events in our local region, and, in part, to the way beings like us deliberate and reason. Some perspectivalists argue that it is necessary for deliberation that we carve the world into two categories - options and fixtures. Options includes the alternatives from which a deliberator chooses, and fixtures includes those matters the deliberator takes herself to know and those matters she regards as at least in principle knowable before any choice is made (Price 2007). ${ }^{\mathrm{vi}}$ A deliberator cannot treat a matter as something to be decided by the deliberative process whilst at the same time taking it as fixed, and she must treat some matters as fixed and thus the basis upon which to deliberate. Thus deliberators must partition the world into fixtures and options. But what things an agent puts into each partition is, the perspectivalist argues, a result of his or her perspective. That is because it is a contingent matter that we have epistemic access to events in one direction (what we call the past) but not the other. To see this perspectivalists ask us to imagine something known as a Gold universe. A Gold universe looks like our universe (and might be our universe for all we know) except that each temporal end of it is a mirror image of the other temporal end. Thus where entropy increases in one direction away from a boundary, entropy decreases towards the other boundary. Perspectivalists argue that from the perspective of agents located at the other end of the universe things would seem just the same as they do at the opposite end. But the direction those at one end call future would be the direction 
those at the other end call past, and what the former call earlier-to-later is what the latter call later-to-earlier. These agents would have quite different views about which events are earlier than which others, and, according to the perspectivalist, there is no fact of the matter who is right, or, alternatively both are right given their particular perspective (Price 2007).

Thus undemanding realists share with middle-way realists the thought that some of what the hard-nosed realist attributes to time ought to be attributed to our subjective experience of the world around us; but they go further than the middle-way realist in locating more features in our subjective perspective and fewer in the nature of time itself. ${ }^{\text {vii }}$

Barbour (1999; 1994a; 1994b), Deutsch (1997) and Rovelli (2001; 2004; 2009), on the other hand, are undemanding error theorists. They hold, very roughly, that our world is a configuration space of three-dimensional instants. Each threedimensional 'instant' is an arrangement of particles in the three spatial dimensions. So each such object looks like a snapshot of our world at a single moment. But according to this view not only are there no dynamical relations between these threedimensional instants, there are no causal or temporal relations between them either. They are not related even by the static B-relations of earlier than, later than, and simultaneous with. It is not true that an event in one instant is the cause of an event at some other instant. Instead, there is one big static configuration space of such instants, and that is all. There is no sense in which the moments (and events and objects) in our world are, as it were, strung out along a linear dimension such that each moment has a place along that dimension and such that there is a metric of distances between said moments. Instead, there are no connections between these moments (and the events and objects located at them) other than relations of similarity. By and large it seems as though these physicists agree that if the world were the way the undemanding realist says it is, then our world would contain time. But since they think our world is not that way they conclude that temporal error theory is true

Thus our final matrix looks like this:

\begin{tabular}{|l|l|l|}
\hline & Realist & Error theorist \\
\hline Hard-nosed category & $\begin{array}{l}\text { Presentists: Tallant, Crisp, } \\
\text { Bourne, Zimmerman; }\end{array}$ & $\begin{array}{l}\text { McTaggart, Gödel, } \\
\text { traditional Dzogchen }\end{array}$ \\
\hline
\end{tabular}




\begin{tabular}{|c|c|c|}
\hline & $\begin{array}{l}\text { Sautrāntikas, Theravādins. } \\
\text { Growing block theorists: } \\
\text { Tooley, Forrest. } \\
\text { Moving spotlight theorists: } \\
\text { Skow, Cameron, } \\
\text { Sarvāstivādin school, } \\
\text { Dōgen, } \\
\text { Other Dynamical Views: } \\
\text { Longchenpa, }\end{array}$ & $\begin{array}{l}\text { practitioners } \\
\text { Nāgārjuna(1) }\end{array}$ \\
\hline Middle-way Category & $\begin{array}{l}\text { Albert, Callender and } \\
\text { Suhler, Ismael, Mellor, } \\
\text { Horwich, Nāgārjuna(2) }\end{array}$ & Nāgārjuna(1) \\
\hline Undemanding Category & $\begin{array}{l}\text { Price } \\
\text { Nāgārjuna(2) }\end{array}$ & $\begin{array}{l}\text { Barbour, Deutsch, Rovelli } \\
\text { Nāgārjuna(1) }\end{array}$ \\
\hline
\end{tabular}

\section{Conclusion}

In general there are a couple of interesting lessons to take away from this matrix. The first is that when we look across the rows we see agreement along one axis and disagreement along another. We see what we might call conceptual agreement: that is, agreement about the concept of time. For any view in the same row agrees about what it takes for time to exist. We also see ontological disagreement across the rows: disagreement about the way the world is. When we look straight down the columns, by contrast, we see conceptual disagreement: disagreement about what it takes for there to be time. Thus even though the first column is populated by temporal realists, we should be careful in thinking that these views have more in common than they really do: for the views that temporal realists in each row in that column defend are quite different from one another. Likewise, when we look down the second column we find all temporal error theorists, but again, we need to be careful not to conclude that these views share much in common. Apparent agreement can really amount to quite a lot of disagreement. Conversely, there is scope to see interesting ontological 
agreement along the right/left diagonal. For instance, in some cases the hard-nosed error theorist will agree with the middle-way realist about the way the world is but will disagree about what it takes for there to be time (conceptual disagreement). Likewise, some middle-way error theorists will agree with undemanding realists about the way the world is but disagree about whether this means there is time (conceptual disagreement).

Thus a careful exploration of the rows, columns, and diagonals of this matrix gives us a much better, more nuanced, picture of the possible versions of temporal realism and temporal error theory that are out there, and a better idea with respect to what views in different boxes are agreeing and disagreeing.

\section{References}

Albert, D. (2000). Time and Chance. Harvard University Press.

Anderson, E. (2006) Relational Particle Models: 1. Reconciliation with Standard Classical and Quantum Theory. Classical and Quantum Gravity, 23(7), 24692490.

Anderson, E. (2009) Records Theory. International Journal of Modern Physics D, $18(4), 635-667$.

Anderson, E. (2012) Problem of Time in Quantum Gravity. Annalen der Physik, 524(12), 757-786.

Barbour, J. (1999). The End of Time. (Oxford; New York: Oxford University Press). . (1994a) The Timelessness of Quantum Gravity: I. The Evidence from the Classical Theory. Classical Quantum Gravity, 11(12), 2853-2873.

. (1994b) The Timelessness of Quantum Gravity: Ii. The Appearance of Dynamics in Static Configurations. Classical Quantum Gravity, 11(12), 28752897.

Baron, S., Evans, P., and Miller, K. (2010) From Timeless Physical Theory to Timelessness. Humana Mente, 13, 35-59.

Bourne, C. (2006) A Future for Presentism. (Oxford: Oxford University Press). 
Cameron, R. (2015). The Moving Spotlight: An Essay on Time and Ontology. OUP.

Crisp, T. M. (2003). “Presentism.” In Michael J. Loux \& Dean W. Zimmerman (eds)

The Oxford Handbook of Metaphysics. Oxford University Press.

Deutsch, D. (1997) The Fabric of Reality: The Science of Parallel Universes and Its Implications. Penguin.

Fine, K. (2006). “The Reality of Tense”. Synthese 150(3): 399-414

Forrest, P. (2006). Uniform Grounding of Truth and the Growing Block Theory: A Reply to Heathwood. Analysis 66(290): 161-163.

Garfield, J.L. (1995). The Fundamental Wisdom of the Middle Way: Nāgārjuna's Mūlamadhyamakakārikāa. New York: Oxford University Press.

Gödel, K. (1949) An Example of a New Type of Cosmological Solutions of Einstein's Field Equations of Gravitation. Review of Modern Physics, 21, 447-450.

Heine, S. (1985). Existential and Ontological Dimensions of Time in Heidegger and Dōgen, SUNY Press, Albany

Horwich, P. (1989). Asymmetries in Time: Problems in the Philosophy of Science. Bradford Books.

Ismael, J. (2002) Rememberances, Mementos and Time-Capsules. In Time, Reality \& Experience. Craig Callender (Ed.), 317-328. (Cambridge: Cambridge University Press).

Kalupahana, J. T. (1974). "The Buddhist Conception of Time and Temporality". Philosophy East and West 24(2): 181-191.

Kutach, D. (2011). "The Asymmetry of Influence" in Craig Callender (ed). Oxford Handbook of Philosophy of Time. OUP.

Longchenpa (Klong-chen rab-'byams-pa), Kindly Bent to Ease Us: From the Trilogy of Finding Comfort and Ease (Ngal-gso skor-gsum), 3 vols, trans. from the Tibetan and annotated by Herbert V. Guenther (Emeryville, CA: Dharma Publishing, 
1975-1976), vol. 1, p. 196.

McTaggart, J. M. E. (1908) The Unreality of Time. Mind, 17(68), 457-474.

Mellor, D. H. (1981). Real Time. Cambridge. Cambridge University Press.

Maudlin, T. (2007) The Metaphysics Within Physics. Cambridge University Press.

Maudlin, T. (2002) Thoroughly Muddled Mctaggart: Or, How to Abuse Gauge Freedom to Create Metaphysical Monstrosities. Philosopher's Imprint, 2(4), $1-23$.

Price, H. (1997) Time's Arrow and Archimedes' Point. (Oxford: Oxford University Press).

Price, H, (2007). "Causal Perspectivalism: In H Price and R Corry (eds). Causation, Physics and the Constitution of Reality: Russelll's Rpublic Revisited. OUP.

Rovelli, C. (2007) The Disappearance of Space and Time. In The Ontology of Spacetime. Dennis Dieks (Ed.), 25-36. (Amsterdam: Elsevier). . (2009) “Forget Time.” ArXiv: 0903.3832. http://fr.arxiv.org/abs/0903.3832. . (2004) Quantum Gravity. (Cambridge: Cambridge University Press).

Siderits, M, and S Katsura (2013). Nāgārjuna's middle way. Mūlamadhyamakakārikā. Wisdom Publications, Boston.

Skow, B. (2012). "Why Does Time Pass?” Nous 46(2): 223-242.

Stambaugh, J (1990). Impermanence is Buddha-Nature: Dōgen's Understanding of Temporality, University of Hawaii Press, Honolulu.

Suhler, C, and C Callender (2012). "Thank Goodness That Argument is Over: Explaining the Temporal Value Asymmetry.” Philosophers' Imprint 12 (15):1-16. 
Tallant, J. (2010) A Sketch of a Presentist Theory of Passage. Erkenntnis, 73(1), 133140.

Tallant, J. (2008) "What Is It to "B" a Relation?” Synthese, 162, 117-132.

Tallant, J (2014). “Defining Existence Presentism” Erkenntnis (79)3: 479-501.

Tooley, M. (2000). Time, Tense and Causation. Oxford. Oxford University Press.

Vorenkamp, D. (1995). "B-Series Temporal Order in Dōgen's Theory of Time". Philosophy East and West 45(3): 387-308

Yao, Z. (2007). "Four-dimensional time in Dzogchen and Heidegger" Philosophy East and West 57(4): 512-532.

Zimmerman, D. W (2008). "The Privileged Present : Defending an "a-Theory" of Time". In Theodore Sider, John Hawthorne \& Dean W. Zimmerman (eds.), Contemporary Debates in Metaphysics. Blackwell: 211--225

\footnotetext{
${ }^{i}$ See also Anderson $(2006 ; 2009 ; 2012)$ and Baron, Evans and Miller (2010) for a discussion of these views.

ii Or what appears to be the same sentence in Sanskrit, Tibetan, or German.

iii At least, there is no requirement that time is globally anisotropic, though on such views it might be that there are local extrinsic anisotropies.

${ }^{\text {iv }}$ Of course technically the moment we are in causal contact with is always slightly in the past because, inter alia, light takes time to hit our retina and to be processed by the brain.

${ }^{\mathrm{v}}$ Perhaps from different inertial frames.

vii Although undemanding realists set the bar relatively low for what is necessary for there to be time, and typically they think that the world yields only this minimal structure, if they were to discover that the world contained more structure - the kind posited by the middle-way and hard-nosed realist - they would still think that there is time. Likewise, the middle-way realist typically thinks that only the medium amounts of metaphysical structure required by middle-way views about time actually obtain. But they will agree that if there is more structure still — such as that posited by the hard-nosed realistthen there is still time.
} 